Alma Mater Studiorum - Università di Bologna DEPARTMENT OF ECONOMICS

\title{
Mortality Salience, Self-esteem and Status Seeking
}

Caterina Giannetti

Raimondello Orsini

Quaderni - Working Paper DSE N910

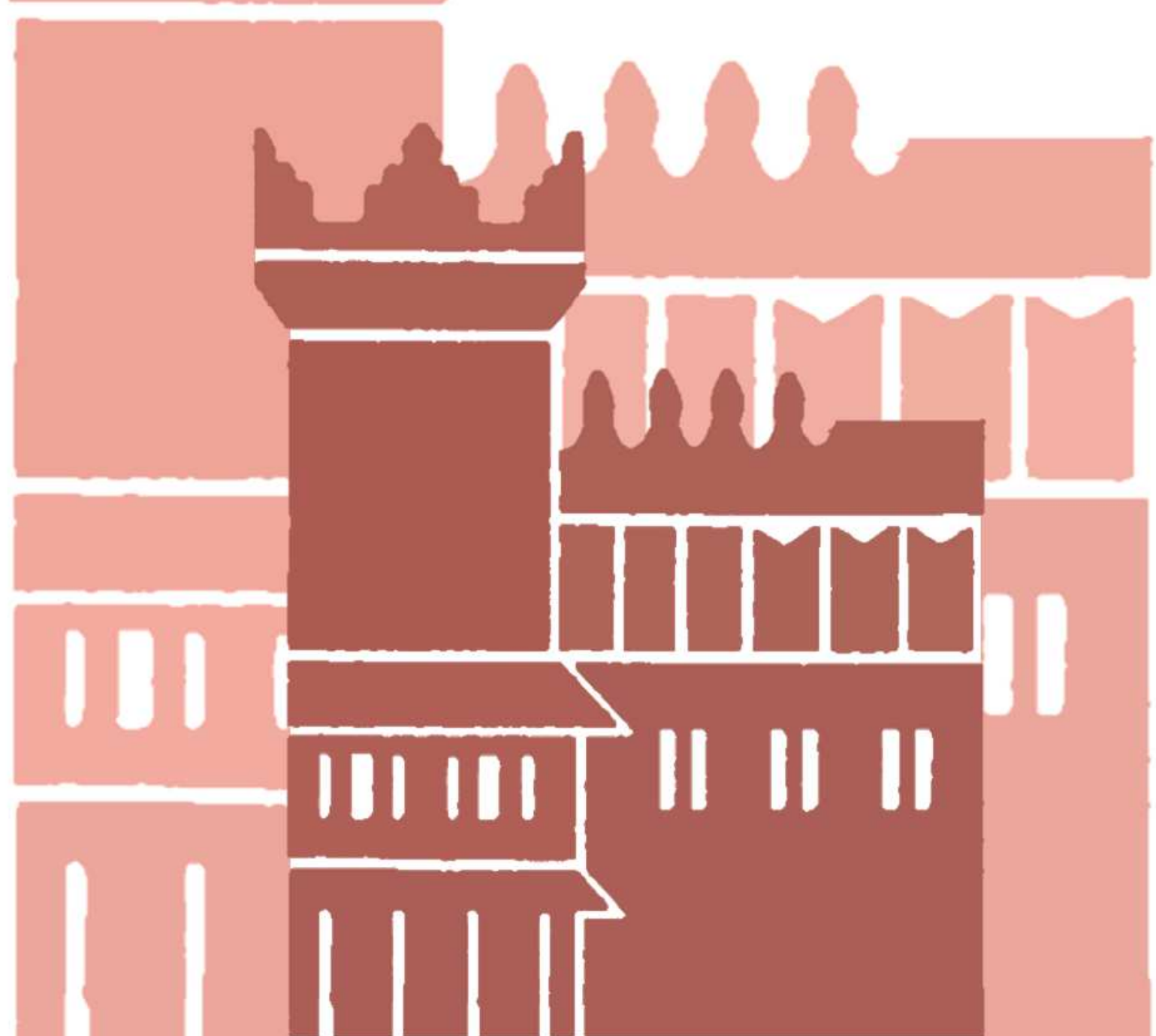




\title{
Mortality Salience, Self-esteem and Status Seeking
}

\author{
Caterina Giannetti ${ }^{1}$ Raimondello Orsini ${ }^{2}$
}

16th October 2013

\begin{abstract}
According to the Terror Management Theory, the fear of death may induce anxiety and threaten individual self-esteem. To remove this fear, individuals need to obtain and sustain self-esteem, for example by competing in rank order tournaments, or by focusing on status seeking. Within an experimental setting, this paper investigates the effect of Mortality Salience on individual productivity, manipulating the information on subjects' relative performance in a real-effort task where the economic incentive is to not perform: in a first treatment subjects receive only private feedback, which may have effects on productivity via individual self-esteem, while in a second treatment subjects receive public feedback, which may have effects on productivity via status seeking. Our results suggest that the majority of subjects exposed to death-related thoughts tend to be more sensitive to in-group conformity when both types of feedback are provided.
\end{abstract}

Keywords: Terror Management Theory, Self-esteem, Status, Feedback

JEL Classification: C91; C92; D12

${ }^{1}$ Corresponding author. University of Bologna. Department of Economics. Email: caterina.giannetti@unibo.it

${ }^{2}$ University of Bologna. Department of Economics. Email: raimondello.orsini@unibo.it

This research has benefited from discussions with a number of people. We would like to thank Maria Bigoni, Elisa Ciaramelli, Fabio Galeotti, Alexia Gaudeul, Antonino Rotolo as well as participants at SONIC meeting and internal seminar at University of Bologna. 
Man is but a reed, the most feeble thing in nature; but he is a thinking reed. The entire

universe need not arm itself to crush him. A vapour, a drop of water suffices to kill him. But, if the universe were to crush him, man would still be more noble than that which killed him, because he knows that he dies and the advantage which the universe has over him; the universe knows nothing of this.

Blaise Pascal, Pensées.

\section{Introduction}

As humans we are all aware our life will come to an end, and we all - at least once in our life experienced the terror of thinking about our death. According to the Terror Management Theory (TMT), which goes back to the work of Ernst Becker (1973), the fear of death has a unique effect on human life due to its potential to induce overwhelming anxiety and to threaten our self-esteem. According to Becker, to avoid living in a state of paralyzing terror, we seek to deny this threat and bolster our self-esteem by conforming to a variety of cultural belief systems that serve to drive away the thoughts of death. This view is also consistent with several philosophers' view, such as Kierkegaard, Nietzsche, Rank, Sartre, and Tillich (see Arndt et al. (2004a)). Cultural beliefs are socially constructed and are shared by groups of people in a certain place and at a certain time. Although faith in these cultural beliefs is an essential means by which we afford protection from existential insecurity, it is not itself sufficient. As humans we also need to feel that we are significant contributors to our vision of a meaningful universe (Becker (2007)); in other words, we need to obtain and sustain self-esteem. The TMT hypothesizes that when the mortality salience increases, we express stronger belief in our cultural worldviews, for example by focusing on material values (e.g. consumption, brand connections), and - to the extent that self-esteem provides protection against concerns regarding death - should increase those behaviours that we believe will result in feelings of self-worth (e.g. conspicuous consumption, work overtime). Substantial evidence confirms the reliability of this theory across a variety of countries and demographic samples (see Arndt et al. (2004b), Solomon et al. (2004)).

Despite the increasing numbers of research on this topic in psychology, however, the association of mortality salience and economic behaviour has not been fully investigated yet. In this context, for example, psychologists have studied whether the fear of death instigates subjects' identification with a cultural worldview in which individuals purchase symbolic goods to reflect one's value (see, for example, Arndt et al. (2004b)). To the best of our knowledge, however, these studies do not rely on incentive-compatible mechanisms, which are instead at the core of the experimental research in economics. On the contrary, we believe that - in addition to selfesteem - economic incentives provide important additional drivers to individual behaviour. In this experiment, we aim to fill this void by relying on an experimental analysis, which combines the main results of TMT (in terms of priming subjects with death-related thoughts) and the ex- 
perimental economic setting (in terms of paying subjects to perform a real-effort task). More specifically, the aim of this research is to study the effect of mortality salience on individuals' effort to gain self-esteem and social status when the economic incentives direct individuals to exert no effort. We define status as the individual's relative standing in a peer-group, and we induce it in the laboratory by providing subjects with public feedback information on their relative performance (i.e. their rank). However, since ranking information may affect individual self-esteem even in the absence of observability by others, we run treatments in which subjects receive rank information privately. From a methodological point of view - similarly to Charness et al. (2013) - we chose to implement a flat-wage scheme, which implies that subjects receive a fixed amount of money disregarding their performance in the real-effort task. In this way, we can isolate the effect of ranking from the one associated to the monetary benefits in other schemes (such as piece-rate) as subjects have no economic incentives to exert a positive effort.

Several papers have studied the effects of feedback on relative performance. Apart from few exceptions (Barankay (2011)), they tend to find a positive effect of rank feedback on performance. Under a flat-wage scheme, Falk and Ichino (2006) and Mas and Moretti (2009) show that when workers can observe each other's output there is an increase in productivity. Kosfeld and Neckermann (2011) show in a field experiment that providing subjects with a congratulatory card for the best performance substantially increases performance. Kuhnen and Tymula (2009) also provide experimental evidence that individual's utility is affected by private information regarding their relative performance. Individuals work harder and expect to rank better when told that they may learn their ranking. Azmat and Iriberri (2010) exploit a natural experiment that took place in a high school finding that students reacted to feedback information on relative performance even though they did not receive any explicit reward (penalty) from performing above (below) the average. Overall, they find a 5\% increase in students' grades. Charness et al. (2013) additionally find out that providing feedback on individual performance can even lead individuals to undertake unethical behaviour (e.g. sabotage). Under piece-rate and tournament schemes, there is also supporting evidence that providing feedback tends to increase performance. For example, Azmat and Iriberri (2011) find that providing subjects with relative performance feedback information increases individual performance, and inequality in happiness and feeling of dominance. However, under this scheme is empirically difficult to find out whether individuals care about their rank or they simply care about the monetary benefits that are associated with it. In addition, money can have different and sometime contradictory effects in case of an increase in mortality salience depending on the norms which are salient in the situation (Jonas et al. (2002)).

Since the experimental economic literature as shown different intensity of the effects depending on both the types of feedback and the wage scheme, in this experiment we aim to disentangle the effect of private and public feedback on individual performance under a flat- 
wage scheme. In this way we can consequently identify - out of any monetary benefit - the effect of private feedback on self-esteem, which does not require public recognition, from the effect of public feedback on status seeking, which instead requires some form of recognition from other members in the group. As our main objective is to investigate individual tendency to outrank their peers when mortality salience increases, our experiment thus consists in a $2 \times 2$ treatments. In the baseline treatments, each period we randomly match participants in groups of three, we ask them to perform a real-effort task (i.e. summations), and we then provide individuals either with private or public feedback on ranking. In our mortality-salience treatments, we run similar treatments but individuals are reminded of their own death before starting the experimental game. In line with previous research in psychology, we expect to find a greater effect when mortality salience increases as subject quest for self-esteem and status. We also expect to find a stronger effect in case of public feedback, as the observability by others affects both self-esteem and status. Economically speaking, however, in no treatment, under the flat-wage scheme, subjects should exert an effort above the minimum (i.e. zero).

Our results suggest that when they are primed with death-related thoughts, the majority of subjects tend to perform more equally. That is, the distributions of the number of points under mortality salience have substantially lower variability than the distributions of the number of points under the control priming topic. For a subset of (less materialistic) participants, however, we constantly observe a higher level of performance. It seems that for this group of subjects, the driver of self-esteem is never overtaken by the economic incentive to play the minimum effort. This is true when subjects are provided with both private and public feedback. Public feedback instead has no effect per se when subjects have already been primed with mortality thoughts, as if intrinsic motivation of individuals and not individuals' need for public recognition drive subjects' behaviour. Importantly, we find that these effects are robust when controlling for a number of individual characteristics, such as age, sex, mathematical ability, personal and social development.

The remainder of the paper is structured as follows: Section 2 introduces the Terror Management Theory, Section 3 presents the experimental analysis and discusses the main challenges of our experimental design. Section 4 presents the results and Section 5 summarizes and concludes our argument.

\section{Terror Management Theory}

A substantial body of evidence illustrates that the thoughts of one's own death affect a wide range of human activities, including creativity, risk-taking, close relationships, sexual attitudes, identification with groups, nationalism and prejudices. For example, a variety of experiments have found that after priming subjects with death-related thoughts, subjects exhibit enhanced 
reactions towards those who break the rules (legal or social and cultural norms), a greater sense of social affiliation - from social group identity to patriotic identification (Greenberg et al. (1997)), and a more materialistic and greedy behavior (Kasser and Sheldon (2000)). Subjects also become more sensitive to famous luxurious brands and change their subjective evaluation of time (Simon et al. (1997)).

According to the Terror Management Theory, individuals gain protection from death-related fear through culture, which enables them to feel "valuable contributor to a meaningful universe". More specifically, in order to provide an anxiety buffer, an effective terror management requires two ingredients:

1. faith in a meaningful conception of reality (the cultural worldview);

2. belief that one is meeting the standard of value prescribed by that worldview (self-esteem).

Since these two ingredients protect from potential terror, people are motivated to maintain faith in their cultural worldviews and satisfy the associated standards of value. The development psychology explanation of the mechanism at work starts from the recognition that self-esteem and recognition by others are substitutes of love and protection by parents. The child meets the standards of his parents to assure himself protection from outside, while conditional disposition of affection is the tool parents use to get a conform child who behaves appropriately and properly (Solomon et al. (2004)). Parental disapprobation induces insecurity (associated with the prospect of parental abandonment). Hence, very early in life, children come to equate being good with being safe, and being bad with the anxiety of being insecure (Sullivan (1953)). However, cultures often value different and sometime contradictory worldviews. Especially in regard to the attitudes one should have towards money, cultural norms often encourage both generosity and accumulation of material wealth. The view that will prevail in case of an increase in mortality salience will in general depend on the norms which are salient in the situation (Jonas et al. (2002)). The aim of our experimental analysis is to disentangle the effects of an increased mortality salience on individual performance via self-esteem and status-seeking - out of any monetary benefit - when subjects are provided with feedback on their relative performance. As highlighted in the next section, the advantage of our design is to combine an incentivized real effort task with the priming on death-related thoughts.

\section{Experimental Analysis}

Few experimental studies have analyzed the role of status and social recognition on individual performance relying on a flat-wage scheme.

The work of Charness et al. (2013) particularly inspired our research. They study whether individuals care about their status in a setting where status derives from receiving more or less 
salient information about their relative position in their group (i.e. public feedback). Relative position is determined by participants' performance in a real-effort task. One of the major results of their study is that individual performance is influenced by feedback on one's relative position in the group, as people tend to exert higher effort when they publicly receive information about their rank. They additionally find out that providing feedback on individual performance can lead individuals to sabotage their peer's performance. The work of Kosfeld and Neckermann (2011) is also closely related. In a field experiment, they study the impact of social recognition on students' performance finding that providing subjects with a congratulatory card for the best performance increases performance by about $12 \%$. Azmat and Iriberri (2010) exploit a natural experiment in a Spanish school where, for one year only, students were provided with relative performance feedback information in addition to the usual individual performance information. More specifically, students could observe whether they were performing above or below their classmates' average. They find that the feedback information had a strong positive effect on students' performance increasing students' grade by about $5 \%$. Importantly, they do not find any discouraging effect on those subjects who performed below the mean.

By using a flat-wage scheme, the major advantage of these experiments is to disentangle the effect of monetary returns from that of performance comparisons. If individuals do not care about social recognition, theory predicts that any feedback or purely symbolic awards will have zero effect on individuals' performance since effort is costly. But if individuals care about social recognition, a positive effort should be observed.

A number of experimental papers, which do not rely instead on flat-wage scheme, are also closely related to our research. Azmat and Iriberri (2011) study in the lab the effect of the provision of informational feedback on agents' performance and affective response (i.e. emotional state). They find that providing subjects with relative performance feedback information increases individual performance, and affects greatly subjects w.r.t. feeling of dominance and happiness. In particular, they find a stronger effect under piece-rate incentives, whereas the effect under flat-rate incentives is milder. There is no status-seeking in this setting, however, as individual information is kept private. Similarly, in a field experiment, Barankay (2011) does not find any positive effect of providing participants with feedback information about how they rank compared to others. On the contrary, he finds a negative effect on both workers' extensive (i.e. decision to go back to work) and intensive margins (i.e. performance). Eriksson et al. (2009) also provide individuals with feedback on relative performance, and they do not find any significant effect under both piece-rate and tournament. However, they observe a negative effect on quality (i.e. more mistakes) among low-performance workers. On the other hand, Blanes i Vidal and Nossol (2011) find that when piece-rate incentives are used, providing individuals with relative performance feedback increases productivity.

In this latter group of experiments, however, the information about individual rank is not 
common knowledge among the group of participants but remains private information for the entire experiment. To clearly understand the role of "status as an incentive", a distinction needs to exist between private and public feedback. In contrast with competitive preferences, which are based on self-esteem, status seeking requires some form of public recognition, and thus feedback information about relative performance must be common knowledge among the group of participants. In fact, those persons that value status per se might believe that their relative position in a group serves as a signal to others about their intrinsic competence and value (Rustichini (2008), Charness et al. (2013)). In this regard, the paper of Tran and Zeckhauser (2012) is illuminating. They find a positive effect of both private and public feedback on students' English tests score. Since there were no monetary benefits involved in this experiment, the evidence is thus consistent with the idea that ranking can provide inherent incentive to perform, either to increase self-esteem or status. Therefore, distinguishing between private and public feedback is crucial if one wants to study self-esteem and status as an "incentive".

\subsection{Experimental design}

To identify the effect of mortality salience via self-esteem and status-seeking, we run two treatments: with Mortality Salience (MS) and with Music. In line with the TMT research, the mortality salience consists of reminding subjects of their own death so that subjects are primed before conducting the real-effort task. The standard procedure consists in two questions to be answered briefly asking participants to describe the emotions that the thought of their own death arouses in them and what would happen to them as they physically die. ${ }^{1}$ To measure the success of the priming strategy, we additionally run an incidental memory test (Moscovitch and Talmi (2007)), in which subjects were asked to recall some words that appeared on their screen in a previous and different exercise in which subjects had to compare the lengths of pair-words. The memory test is defined incidental as subjects were unaware that a memory test on the same group of words would have followed. The words were generated on different topics, but half of them were death-related words (such as "funeral", "grave", "putrefaction"). Subjects earned 0.25 cent for each word they were able to remember. As explained in detail further below, the measures we construct from this exercise, along with other control questions, allow us to identify those subjects for which the priming strategy was effective or failed. In the control sessions (i.e. without mortality salience), subjects were asked to write an essay and perform a memory exercise on a control topic (i.e. music).

Participants then filled out the personality questionnaires. The aim of completing such ques-

\footnotetext{
${ }^{1}$ The exact questions to be answered are:

- "Please describe as specifically as you can the emotions that the thought of your own death arouses in you"

- "Please describe as specifically as you can what do you think will happen to you as you physically die".
} 
tionnaire is twofold. First, about ten minutes need to elapse from the priming treatment as individuals' first reaction to conscious thoughts of mortality is to remove them from focal attention activating distal defense (see Arndt et al. (2004a)). Once these direct defenses against conscious thoughts of death are relaxed, death thought accessibility increases outside of conscious awareness. Second, as it will be explained below, personality traits - such as agreeableness and openness - might be correlated with other important aspect which may affect our results (see, for example, Ben-Ner et al. (2004)).

In all treatments, subjects performed a real-effort task (i.e., three-digits summations), which was paid a fixed amount of money disregarding individual's performance (e.g. the number of correct answers). In this way, we rule out relative income feedback (see, for example, Azmat and Iriberri (2010), Charness et al. (2013)). The task was not very difficult and a bit tedious in order to induce some disutility. In addition, subjects knew (as highlighted on the screen and reported in the instructions) they could stop at any time during the experiment. To allow for alternative activities we provided subjects with some magazines and we allowed them to read their own materials. Thereupon, the probability that subjects conducted the real-effort task simply to avoid boredom is substantially reduced (see also Charness et al. (2013)). However, no external aids (calculators, scratch paper, etc) were allowed.

In each period subjects were randomly matched in groups of three participants. At the end of the period, we provided subjects with the number of correct answers and we privately provided them with a ranking of the results in their group. More specifically, subjects were informed whether they ranked "First", "Second" or "Last" in their group (i.e. Private Feedback). We then repeated this exercise for seven periods. At the beginning of each period, we also privately provided each participant with their personal history in the entire game. To further distinguish the effect of pure self-esteem from that of status-seeking, we run the same treatments making the same information available to all participants in each peer group (i.e. subjects could see the entire history of their peers - Public Feedback). We thus have the 2x2 treatments as described in Table (1).

Our main hypothesis (H1) is that in the treatments with mortality salience individuals feel more the psychological pressure to perform (under both private and public feedback on ranking) as their self-esteem has been threatened when they had to think about their own death. By succeeding in the competition, they can recover and maintain their self-esteem. It is not clear a priori, however, what should be the interaction between the economic incentives to not perform and the increase in the mortality salience. If their sensitivity to the flat-wage increases as a result of the augumented materialism (see Kasser and Sheldon (2000), Arndt et al. (2004b)), their quest for self-esteem may be offset by the economic incentives to not perform. We additionally hypothesize (H2) that the effect of self-esteem are reinforced once subjects are publicly informed about their ranking. We should thus observe a greater effect on individuals' perfor- 
Table 1: MORTAlity SAliEnCE (MS): EXPERIMENTAl HyPOTHESES

\begin{tabular}{|c|c|c|}
\hline \multicolumn{2}{|c|}{ TREATMENT } & \\
\hline \hline with Music \& with Private Feedback & with Music \& with Public Feedback & H2: stat. sign. (due to status seeking) \\
\hline with MS \& Private Feedback & with MS \& Public Feedback & H2: stat. sign (due to status seeking) \\
\hline H1: stat. sign. due to MS & H1: stat. sign. due to MS & \\
\hline
\end{tabular}

mance when subjects are publicly informed about their relative performance as the drive of status-seeking is added to the drive of self-esteem. In order to distinguish these effects along the entire distribution of results, we also check for any effect of these treatments on the variance of the effort among participants (see Kosfeld and Neckermann (2011)).

\section{Experimental Results}

The experiment was run between April and May 2013 at the LES Laboratory of University of Bologna in Forlì Campus using z-Tree software (Fischbacher (2007)), and involved 126 students for a total of 9 sessions. The average payoff was about 8.5 Euro. Each session lasted for about one hour and did not start until all participants were familiar with the procedure.

We conducted the experiment for two environments (i.e., treatments with Mortality Salience -MS- and with $M u s i c)$. As explained above, for each environment we considered two settings, with Private Feedback and with Public Feedback.

\subsection{Priming Strategy}

One crucial question for the present study is the success of the (death vs. music) priming strategy. Participants may or may not comply with the request of focusing on their own death, and, more in general, the priming strategy may be differentially effective at activating deathrelated or music-related thoughts across participants. We adopted several measures to assess the efficacy of our priming procedures. First of all, we evaluated whether the contents of the participants' reports were generally consistent with the task demands. They were: in all cases participants wrote about their own death in the MS treatments and about music in the Music treatments. Next, after the MS vs Music treatments, participants rated, on a Likert scale $(1=$ not much; 5 = very much), the effort they put and the intensity of the emotion they felt in writing the essay. Further, in addition to subjective measures, we devised an incidental memory task (Moscovitch and Talmi (2007)) to measure the relative accessibility of death (or music) related concepts after the MS (or Music) treatments. Immediately after writing about death (or music), participants were presented with (32) pairs of words appearing on their computer screen. In each pair, one word was related to the main theme of the treatment - death for the MS treatments (e.g., funeral), music for the Music treatments (e.g., violin) - whereas the other 
Table 2: PRIMING STRATEGY SUCCESS

The variable Total words measures the total number of words subjects were able to remember in the incidental memory test. The variable Treatment words measures the number of death-related words and the number of music-related words subjects were able to remember in the MS and Music treatment respectively. Loss experience represents the share of subjects who experienced a mourning of a beloved in the recent past. Effort is a self-reported indicator which measures the effort subjects put in writing the essay, whereas Emotion measures in a similar way the emotion they prove while writing it.

\begin{tabular}{|l|c|c|c|c|c|c|c|c|c|c|c|}
\hline & \multicolumn{4}{|c|}{ MORTALITY } & \multicolumn{5}{c|}{ MUSIC } \\
\hline & Mean & Std & Min & Max & N & Mean & Std & Min & Max & N & \\
\hline \hline Total words & 6.367 & 4.002 & 0 & 14 & 66 & 4.033 & 3.124 & 0 & 10 & 60 & $\mathrm{p}<0.001$ \\
\hline Treatment words & 2.413 & 3.152 & 0 & 11 & 66 & 1.278 & 2.089 & 0 & 7 & 60 & $\mathrm{p}<0.05$ \\
\hline Loss experience & 0.272 & 0.449 & 0 & 1 & 66 & 0.200 & 0.403 & 0 & 1 & 60 & $\mathrm{p}=0.171$ \\
\hline Effort & 3.433 & 0.871 & 1 & 5 & 66 & 3.379 & 0.696 & 2 & 5 & 60 & $\mathrm{p}=0.349$ \\
\hline Emotion & 2.413 & 0.993 & 1 & 5 & 66 & 3.300 & 1.124 & 1 & 5 & 60 & $\mathrm{p}=0.380$ \\
\hline
\end{tabular}

word was not related to the theme but the same for all treatments. Participants' task was to evaluate which of the two words was longer. In a later surprise memory test, participants were requested to recall as many words they could, with the assumption that those individuals for which the priming procedure was relatively more effective would be more inclined to attend to and successfully encode words congruent with the primed theme, resulting in increased recall rates for death related words (for the MS treatments) and music-related words (for the Music treatments) (e.g., Moores et al. (2003)). Finally, we additionally control for those subjects who experienced a loss in the recent past as these subjects were obviously exposed to death, and somehow "primed", before the experiment.

Table (2) summarizes these control variables. Indeed, there is a substantial difference in the average numbers of words subjects were able to remember in the two settings, as well as in the variability (i.e. std) of the distributions of words. Subjects under the MS treatments were more able to significantly recall a higher number of words. No significant differences, however, emerge in term of self-reported measures of effort and emotion in the task. This table also shows that more than $20 \%$ of subjects experienced a mourning of a beloved in the recent past.

\subsection{Univariate Analysis}

In this section we present a comparative analysis of performance at session level across treatments. Figure (1) displays the distributions of the number of points across the two environments (with MS and with Music) and settings (with Private Feedback and Public Feedback). The number of points measures the number of correct summations entered by subjects in each period of the real effort task. At first sight, it is evident that the distributions of points for the treatments with mortality salience have a different shape in comparison to the distributions of points for the control treatment (i.e. music), both when private and public feedback are pro- 
vided to the subjects. The result of public feedback per se does not seem to be so striking. ${ }^{2}$

To see whether these effects are statistically significant, we first compare across treatments (i.e. with MS and with Music) the mean values of the number of points computed by keeping for each session the average. The results (not reported) from these unpaired tests (TTEST) suggest there are no significant differences in the mean when comparing the distributions according to the priming strategy. There is instead a weak evidence (at 10\% level) for a difference in the mean of the distribution of points under the Public Feedback setting, which is higher than the mean of the distribution of points under the Private Feedback.

From these pictures, however, it is clear that comparing the means is not the right test for these distributions. Indeed the MANN-WITHNEY tests strongly reject in all cases the null hypothesis that groups are drawn from two populations with the same distribution. Overall, this analysis seems to suggest that our priming strategy has a strong effect on the variance of the distributions of points (i.e. lower variance in the treatment with mortality salience), whereas the effect of the public feedback is less clear.

Before proceeding to analyse the data at individual level, it is thus interesting to study what determines the variance of the performance across treatments. To this end we construct a Gini index to measure the inequality in the number of points in each period and session. ${ }^{3}$ The results are reported in Table (4). In column $a$ we start by adding a dummy variable for mortality treatments and public feedback. The coefficient for the mortality treatments is negative and statistically significant suggesting that the variance of the distributions is significantly lower when subjects are reminded of their own death (i.e. a low Gini coefficient indicates a more equal distribution). The coefficient on public feedback instead is not statistically significant. In column $b$ we add an interaction term between these two variables. The public feedback dummy is now statistically significant, whereas the additional effect under the mortality treatment (i.e the interactions term) is positive and significant suggesting that public feedback has an opposite effect on the variability of distributions when subjects are primed with death-related thoughts. From column $c$ to $e$ we add few controls computed at session level (i.e. the average in each session). More specifically, in column $c$ we add the share of subjects in each session who experienced the loss of a beloved, in column $d$ we add the subjects' average ability in mathematics, while in column $e$ we include the share of female along with subjects' average age (see Table (3) for a description of these variables). The inclusion of these variables does not affect our main results: both public feedback under the Music treatment and mortality salience decrease the variability of the distributions of points.

\footnotetext{
${ }^{2}$ These pictures have been drawn including under the mortality treatments also those subjects who experienced a loss in the recent past. The distributions without controlling for loss experience are substantially similar.

${ }^{3}$ The Gini coefficient is generally used as a measure of inequality of income distribution. It is defined as a ratio with values between 0 and 1, where 0 corresponds to perfect equality (everyone having exactly the same income) and 1 corresponds to perfect inequality (where only one person has all the income). Thus, a low Gini coefficient indicates more equal distribution, while a high Gini coefficient indicates more unequal distribution.
} 


\subsection{Multivariate Analysis}

In this section we analyse the subjects' performance under different treatments, while accounting for a number of control variables measured at individual level.

As highlighted above, in our experiment it is crucial to control for the success of our priming strategy. This is confirmed by the empirical analysis of our data. In Table (5), column $a$, the coefficient on the dummy for the MS treatment is negative and statistically significant suggesting that subjects under the mortality treatment enter a lower number of summations. However, when we add in column $b$, the number of words a subjects was able to remember from the incidental memory task in the mortality treatments and in the music control treatments (Words Recall Mortality and Words Recall Music), the coefficient on the treatment dummy remains negative and statistically significant, whereas the coefficient on Word Recall Mortality itself is positive and significant, suggesting that individuals for which the priming strategy was more effective tend to insert a larger number of summations. ${ }^{4}$ At first sight, this result seems to highlight two types of behaviour in the group of subjects primed with death-related thoughts. ${ }^{5}$ One may object that it is due to unobservable subjects' ability which affects both the number of recalled words and the number of summations. However, one needs to notice that the coefficient on World Recall Music is not statistically significant. As a further check, in column $c$ we add subjects past ability in mathematics (Math Ability), ${ }^{6}$ along with a dummy variable equal to 1 for those subjects who experienced the loss of a beloved in the recent past (Loss). Although the coefficient on Math Ability has a positive and significant effect on the number of entered summations, the size and significance on Words Recall Mortality have not changed. The additional control for mortality salience - Loss - does not turn out to be significant. In column $d$ we add a categorical variable (Period), which accounts for possible trends in the experiment. This variable turns out to be positive and significant, suggesting either there is a learning effect (and thus subjects are able to progressively enter a greater number of summations) or subjects become more competitive. It is interesting to note that this effect tends to disappear when subjects are provided with public feedback, while it tends to persist in the treatments with mortality salience (see the interaction terms in column $e$ ). Therefore, as it will be confirmed further below, our subjects tend to become more competitive under the mortality treatment as the time goes by.

\footnotetext{
${ }^{4}$ When we replace the variables with the share of treatment-words a subject was able to remember in the incidental memory test results do not change. We prefer to keep this specification as it easier to interpret: we can interpret the coefficient as the effect arising for one additional word the subject is able to remember.

${ }^{5}$ These two types of behaviour ruled also out the possibility of ego-depletion of our subjects in the MS treatments. If there are individuals who still manage to keep their performance up to and above the average, the main driver of low-performance is not the draining of mental resources.Thus, our results suggest that writing on death-related thoughts is demanding as much as writing about music.

${ }^{6}$ Individual math ability has been measured by asking subjects to rate - from one (i.e. definitely no) to five (i.e. definitely yes) - their agreement with the following statement: "In the past I have proved to have good mathematical skills".
} 


\subsubsection{Robustness checks}

In Table (6), we control for the robustness of our results to a number of controls. As discussed above, an important concern that needs to be checked in our design is related to the use of flatwage and individual attitude to reciprocate (see also Charness et al. (2013)). Even though subjects are provided with alternative activities (i.e. magazines) and are allowed to read their own materials, there is indeed the risk that subjects decide to perform the task as they feel obliged to do "something" once in the lab. Since we had this concern, we collected upfront a series of information about subjects' attitudes to provide effort in the experiment. First, we measured subjects' attitude to reciprocate relying on the following question "If someone does something that is beneficial for you, would you be prepared to return a favour even if this was not agreed upon in advance and may be costly for you"? from which we derive a general indicator of reciprocity. The inclusion of this variable in column $a$ does not alter our results. Second, we control for individual agreeableness and openness (as measured through the short version of the big-five questionnaire at the beginning of the experiment) which have been proved to be highly relevant in explaining reciprocal behaviour of subjects (see Giannetti and Orsini (2013), Ben-Ner et al. (2004)). When we add in column $b$ these alternative proxies for reciprocity (Agreeableness and Openness) our results do not change. Before including additional individual characteristics, in column $c$ we add two indicators on the effectiveness of our priming strategy, which respectively account for the effort subjects exerted (i.e. Priming Effort), and the emotions they proved (i.e. Priming Emotion), while writing their essay. Also in this case the results are the same.

We then control for additional characteristics that turned out to be relevant in previous research on TMT. In particular, females have been often identified to dislike competition and to be less materialistic (see Rindfleisch et al. (2009), Croson and Gneezy (2009)). In column $d$ we thus add participants' age (i.e. Age) and sex (i.e. Female), but even these controls do not add anything to our specification. Finally in column $e$ we add controls on individual's level of uncertainty in relationships with others (i.e. Development Insecurity), in personal skills and abilities (i.e. Personal Insecurity), and in appearance and social interactions (i.e. Social Insecurity). As long as insecure subjects have weaker defense against the fear of death (see Rindfleisch et al. (2009)), the more insecure the subjects, the more likely is the success of our priming strategy. Although Personal Insecurity is slightly significant at $10 \%$ level, the size and significance of the coefficients on the main variable of our interest do not change.

We also need to control for other possible cultural worldviews such as religion beliefs, which might have affected our priming strategy (Arndt et al. (2004b), Rindfleisch et al. (2009)). In particular, when subjects can rely on a greater number of cultural views, the priming strategy is likely to fail. We therefore asked subjects to rate how much family, friends, work and religion are important in their life and included these variables as additional controls. The results (not reported) do not change, and these variables turned out not to be significant. 


\subsection{Dynamics in performance and ranking}

In Table (7), we study the first difference in the number of points to investigate whether there is any effect on the dynamics of performance between treatments. In particular, we are interested to study the effect of previous rank position on the behaviour of the subjects in the current period. In column $a$, we thus add - in addition to the usual variables accounting for the various treatments - a dummy variable which is equal to 1 if the subject ranked first in the previous period (i.e. Ranked 1st (t-1)), and a dummy variable which is equal to 1 if the subject ranked second in the previous period (i.e. Ranked 2nd ( $\mathrm{t}-1)$ ). The base category comprises subjects who ranked 3rd in the previous period (i.e. Ranked 3rd (t-1)). The results seem to suggest there is no treatment effects: the dummy variable on mortality salience is not statistically significant. Instead, the dummy variable on public feedback is negative and statistically significant suggesting that under this setting individuals tend to decrease their performance. The dummy variables on rank positions are both negative and statistically significant, suggesting that individuals who ranked first or second in the previous period tend to reduce their performance in the following period. From column $b$ to $e$, we continue to add our controls for the priming strategy and individual ability. Interesting to note, only the variable measuring the number of words an individual was able to remember in the mortality salience treatments is again positive and slightly significant, whereas mathematical past ability is not significant. These results further suggest that individuals who were successfully exposed to death-related thoughts tend to improve their performance during the task in the quest for self-esteem. We have also tried to interact the variables on past rank with the dummy variables for mortality salience and public feedback. No significant results, however, emerged.

In Table (8) we again study the dynamics between treatments, but this time focusing on ranking rather than on the individual number of correct answers. In column $a$ we see there is no effect arising from the mortality salience and public feedback. The dummy variables on rank positions are again positive and statistically significant, this time suggesting that individuals who ranked in the top positions in the previous period tend to maintain or improve their rank in the following period (i.e. "success breads success"). Along with the previous one, this result seems to suggest that individuals tend to reduce their effort but in a way that still allows them to be among the best performers.

From column $b$ to $d$ we add the usual controls. Once again, the coefficient of the variable accounting for the words subjects was able to remember under the mortality treatment is negative and significant, whereas math ability is not statistically significant. These results further suggest that those individuals for which the priming strategy was more effective tend to rank better in the experiment. However, the interaction between ranking and the dummy accounting for mortality salience is now statistically significant indicating that when subjects are primed with death-related thoughts, they tend to worsen their position if in the previous period they 
were among the best performers. Thus, in the mortality treatment, the reduction of the variance in the number of points we observe in Figure (1) can be attributed to those subjects that tend to reduce their effort once they have gained self-esteem, as well as to those subjects who ranked low and tend to increase their effort. Hence, for this group of subjects the main driver after the mortality salience seems to be the economic incentive to not perform, which tends to overtake the quest for self-esteem, thus resulting on conformism. In other words, at least initially these subjects exposed to death related thoughts tend to exert more effort in the task, in the quest for self esteem and status. However, they have not a clear belief/expectation on the due amount of effort which is required to get ahead in the group rank. As the task goes on and more feedback on their relative performance are available, they adjust their effort to get a decent position without incurring in too much disutility. This process is reasonable and as such it might be at work in any treatment, but we find it statistically relevant only for this group of subjects in the MS treatments. We also tried to interact previous rank positions with the Words Recall Mortality (not reported) to see whether this effect is playing a role also for the smaller group of subjects who recall a higher number of words in the incidental memory test. No significant results emerged. We thus conclude that for this group of subjects the main driver of their behaviour is the constant quest for self-esteem.

In support of this interpretation, we finally split our sample in relation to subjects' level of materialism (results are available upon request). More specifically, we split our sample in two groups: below and above the mean level of an indicator of materialism (collected through the exit questionnaire, see also Rindfleisch et al. (2009)). The distribution of this indicator is negatively skewed (i.e. the mean is below the median) so the second group of subjects is larger than the first group. Consistent with the above discussion, we find that the dummy variable for the MS treatments is negative and statistically significant for more materialistic subjects (i.e. the larger group) whereas the effect of Words Recall Mortality is not statistically significant. The opposite is true for the smaller group of less materialistic subjects.

To sum up, our conclusion is that the MS priming makes the majority of subjects more sensitive to in-group conformity: they do not want to be the last in the rank, but they do not want to be the only members of the group who spend effort either. There is a double target to be hit: not to perform too poorly, and not to appear dumb in working more than needed (as it is not paid). Subjects treated with MS are more sensitive to these two targets, and their behavior tend to be thus more conformist. However, a smaller group of subjects disregard the economic incentive to not perform in the task and constantly keep a high level of performance in the quest for self-esteem. 


\subsection{Discussion}

In line with previous economic experimental analysis (e.g. Charness et al. (2013); Azmat and Iriberri (2010)) we have shown that providing feedback about ranks gives incentives to perform even under a flat-wage. In addition, our results suggest that, when mortality salience increases, the majority of individuals tend to perform more equally. This result is also in line with previous psychology research on mortality salience (see, for example, Kasser and Sheldon (2000), Arndt et al. (2004b)), which shows that individuals tend to become more materialistic (i.e. more sensitive to economic incentives) and less creative (i.e. to reduce differentiation from the majority position) after thinking about death. Subjects therefore tend to minimize the level of their differentiation from others. Moreover, when subjects have been reminded of their own death, we cannot distinguish any additional effect from the provision of a public feedback instead of a private one, as if self-esteem - rather than status-seeking - is the main driver of individual behaviour.

One objection to our experimental design might be that individual exert effort simply to please the experimenter perceived as an authority (Zizzo (2010)) or to behave nicely towards him/her (Giannetti and Orsini (2013)). We believe, however, that these effects are not playing a crucial role in explaining our results. First of all, we avoid having our students in the lab. Second, at the end of the experiment we ask students their opinion about the objectives of our experiment. From the answers they gave, we can be confident they were really uncertain about the objective of the experiment. Indeed our subjects had to compile a variety of questionnaires and perform a series of tasks, thus making really hard for them to find the connections and the "desired" behaviour. Finally, as explained above, we collected and included in our regressions

a large number of controls that have been proved to be associated with nice and reciprocal behaviour (Ben-Ner et al. (2004); Giannetti and Orsini (2013)).

We also check for different specifications of our model. In particular, we check for any selection effect by running a series of Heckman-selection models to see whether there were significant differences between subjects who decided to exert a positive effort and subjects who decided to stay out of the competition. No selection effects have emerged and results are substantially identical.

We are thus confident that our experimental design was able to isolate the effect of mortality salience on individual self-esteem and status-seeking when the economic incentives direct subjects to provide zero effort.

\section{Conclusions}

Humans are the only living beings aware of their own mortality. As postulated by the Terror Management Theory, a large proportion of human behaviour is motivated by the need to 
defend oneself from the existential anxiety that arises from this mortality awareness. By investing in cultural worldviews that provide meanings, individuals obtain protection and an anxiety buffer. The mechanism at work is individual self-esteem: as long as individuals believe they are meeting the standard of value prescribed by the worldview, individuals feel "valuable contributor to a meaningful universe".

The aim of this experiment was to disentangle the effects of an increased mortality salience on individual performance via self-esteem and status-seeking when subjects are provided with feedback on their relative performance and the economic incentive is to not perform. After writing about death or a control topic (i.e. music), our participants performed a real effort task (i.e. three-digits summations) and received - either privately or publicly - feedback on their relative position.

Our results suggest that after mortality salience, a large group of participants tend to conform to others: initially, subjects tend to exert more effort to go ahead in the rank position in the quest for self-esteem, but as the time goes by those who got the best positions tend to reduce their performance to reduce their economic disutility (as they are paid a fixed wage disregarding their performance). For a subset of participants, for which the priming strategy was probably most effective (as they tend to recall the higher death-related words in the incidental memory test), we do not observe such a reduction in performance (and rank positions). The need to maintain self-esteem is - most likely - their main driver of their behaviour. As a result, the distributions of points under the mortality salience exhibits a lower variance than in the control treatments. The effect of public feedback per se does not have instead any additional effect once subjects have been reminded of their own death, as if intrinsic motivation of individuals and not individuals' need for public recognition drives subjects' behaviour.

Our results are in line with previous research on mortality salience (see, for example, Kasser and Sheldon (2000), Arndt et al. (2004b)), which show that when reminded of their own death, individuals tend to become more materialistic and minimize the level of their differentiation from others. In the same way, our subjects tend to conform to the performance of the others when reminded of their own death. Another genuine true we are all aware of: death makes us all equal when it comes. 


\section{References}

Arndt, J., Cook, A., Routledge, C., 2004a. The blueprint of terror management. Handbook of experimental existential psychology, 37.

Arndt, J., Solomon, S., Kasser, T., Sheldon, K. M., 2004b. The urge to splurge: A terror management account of materialism and consumer behavior. Journal of Consumer Psychology 14 (3), 198-212.

Azmat, G., Iriberri, N., 2010. The importance of relative performance feedback information: Evidence from a natural experiment using high school students. Journal of Public Economics $94(7), 435-452$.

Azmat, G., Iriberri, N., 2011. The provision of relative performance feedback information: An experimental analysis of performance and happiness. Universitat Pompeu Fabra Working Paper.

Barankay, I., 2011. Rankings and social tournaments: Evidence from a crowd-sourcing experiment. Tech. rep., Working Paper.

Becker, E., 2007. The denial of death. Free Press.

Ben-Ner, A., Putterman, L., Kong, F., Magan, D., 2004. Reciprocity in a two-part dictator game. Journal of Economic Behavior \& Organization 53 (3), 333-352.

Blanes i Vidal, J., Nossol, M., 2011. Tournaments without prizes: evidence from personnel records. Management science 57 (10), 1721-1736.

Charness, G., Masclet, D., Villeval, M. C., 2013. The dark side of competition for status.

Croson, R., Gneezy, U., 2009. Gender differences in preferences. Journal of Economic Literature 47 (2), 448-74.

Eriksson, T., Poulsen, A., Villeval, M. C., 2009. Feedback and incentives: Experimental evidence. Labour Economics 16 (6), 679-688.

Falk, A., Ichino, A., 2006. Clean evidence on peer effects. Journal of Labor Economics 24 (1), 39-58.

Fischbacher, U., June 2007. z-tree: Zurich toolbox for ready-made economic experiments. Experimental Economics 10 (2), 171-178.

Giannetti, C., Orsini, R., 2013. Being nice with the experimenter? mimeo. 
Greenberg, J., Solomon, S., Pyszczynski, T., 1997. Terror management theory of self-esteem and cultural worldviews: Empirical assessments and conceptual refinements. Advances in experimental social psychology 29, 61-139.

Jonas, E., Schimel, J., Greenberg, J., Pyszczynski, T., 2002. The scrooge effect: Evidence that mortality salience increases prosocial attitudes and behavior. Personality and Social Psychology Bulletin 28 (10), 1342-1353.

Kasser, T., Sheldon, K. M., 2000. Of wealth and death: Materialism, mortality salience, and consumption behavior. Psychological Science 11 (4), 348-351.

Kosfeld, M., Neckermann, S., 2011. Getting more work for nothing? symbolic awards and worker performance. American Economic Journal: Microeconomics 3 (3), 86-99.

Mas, A., Moretti, E., 2009. Peers at work. American Economic Review 99 (1), 112-45.

Moores, E., Laiti, L., Chelazzi, L., 2003. Associative knowledge controls deployment of visual selective attention. Nature neuroscience 6 (2), 182-189.

Moscovitch, M., C. J., Talmi, D., 2007. Learning, memory, \& knowledge. In: (Ed.), B. B. (Ed.), Cognition, Brain, and Consciousness. Elsevier Science, Amsterdam, pp. 397-405.

Rindfleisch, A., Burroughs, J. E., Wong, N., 2009. The safety of objects: Materialism, existential insecurity, and brand connection. Journal of Consumer Research 36 (1), 1-16.

Rustichini, A., 2008. Dominance and competition. Journal of the European Economic Association $6(2-3), 647-656$.

Simon, L., Greenberg, J., Harmon-Jones, E., Solomon, S., Pyszczynski, T., Arndt, J., Abend, T., et al., 1997. Terror management and cognitive-experiential self-theory: Evidence that terror management occurs in the experiential system. Journal of personality and social psychology 72, 1132-1146.

Solomon, S., Greenberg, J., Pyszczynski, T., 2004. The cultural animal: Twenty years of terror management theory and research.

Sullivan, H. S., 1953. The interpersonal theory of psychiatry.

Tran, A., Zeckhauser, R., 2012. Rank as an inherent incentive: Evidence from a field experiment. Journal f Public Economics 96 (9-10), 645 -650.

Zizzo, D. J., 2010. Experimenter demand effects in economic experiments. Experimental Economics 13 (1), 75-98. 


\section{Figure 1: Distributions OF POINTS ACROSS TREATMENTS}
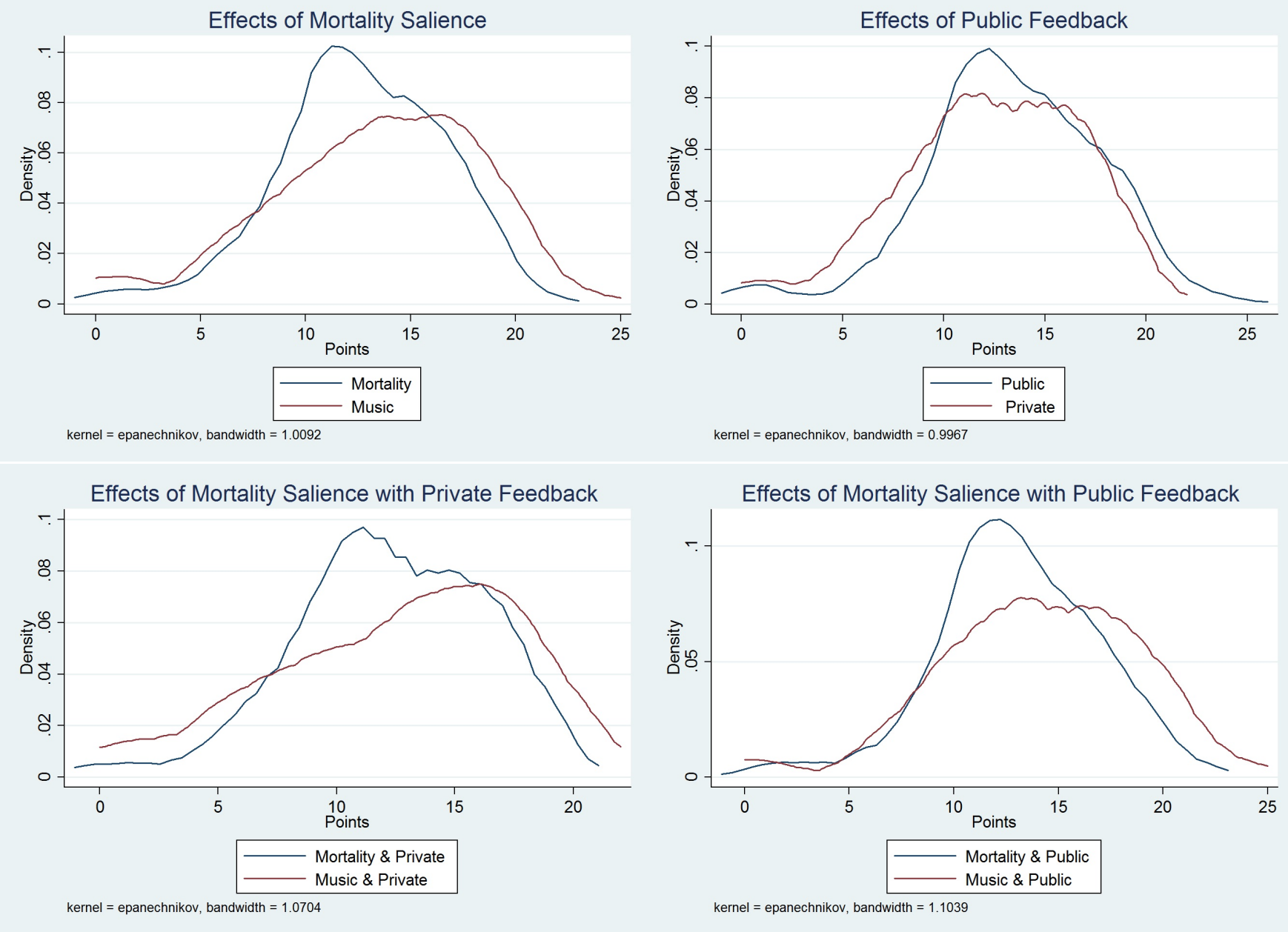


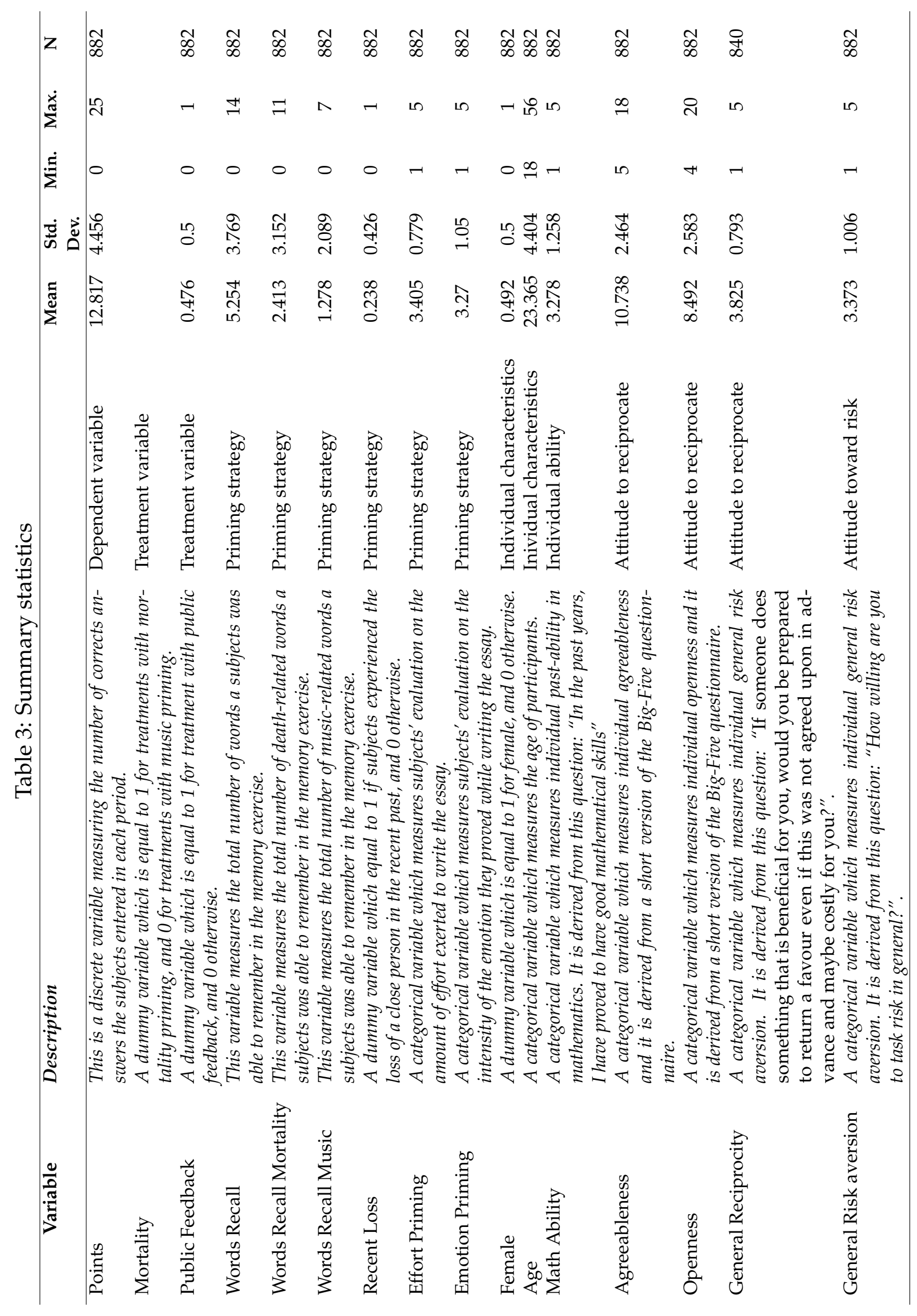


Table 4: Performance inequality (Session Gini Index) across Treatments

The dependent variable is the Gini index of the point distribution computed at session level for each period (i.e. 9 sessions for 7 periods). Mortality is a dummy variable equal to 1 for sessions with mortality salience and 0 otherwise, whereas Public Feedback is equal to 1 for sessions with public feedback and 0 otherwise. Average Loss is the share of participants in each session that experienced a loss in the recent past (i.e. the session average of Loss), Average Math Ability is the average subjects' ability in mathematics in each session (i.e. the session average of Math Ability), Average Age is the average subjects' age in each session, and Average Female is the share of female participants in each session (i.e. the session average of Female). See Table (3)).

\begin{tabular}{lccccc}
\hline & $a$ & $b$ & $c$ & $d$ & $e$ \\
\hline Mortality & $-0.0360^{* * *}$ & $-0.0565^{* * *}$ & $-0.0589^{* * *}$ & $-0.0491^{* * *}$ & $-0.0477^{*}$ \\
& $(0.009)$ & $(0.012)$ & $(0.013)$ & $(0.013)$ & $(0.028)$ \\
Public Feedback & -0.0070 & $-0.0315^{* *}$ & $-0.0315^{* *}$ & $-0.0315^{* *}$ & $-0.0381^{* *}$ \\
& $(0.009)$ & $(0.013)$ & $(0.013)$ & $(0.013)$ & $(0.017)$ \\
Public Feedback${ }^{*}$ Mortality & & $0.0450^{* *}$ & $0.0619^{*}$ & 0.0544 & 0.0582 \\
& & $(0.018)$ & $(0.034)$ & $(0.033)$ & $(0.036)$ \\
Average Loss & & & -0.0726 & -0.0651 & 0.0560 \\
& & & $(0.124)$ & $(0.119)$ & $(0.181)$ \\
Average Math Ability & & & & $0.0373^{* *}$ & 0.0157 \\
& & & & $(0.015)$ & $(0.039)$ \\
Average Age & & & & & -0.0141 \\
& & & & & $(0.016)$ \\
Average Female & & & & & 0.0214 \\
& & & & $0.149)$ \\
Constant & $0.1761^{* * *}$ & $0.1883^{* * *}$ & $0.2029^{* * *}$ & 0.0771 & 0.4389 \\
& $(0.008)$ & $(0.009)$ & $(0.027)$ & $(0.056)$ & $(0.471)$ \\
\hline Observations & 63 & 63 & 63 & 63 & 63 \\
\hline \hline
\end{tabular}

${ }^{*} \mathrm{p}<0.10,{ }^{* *} \mathrm{p}<0.05,{ }^{* * *} \mathrm{p}<0.01$ 
Table 5: INDIVIDUAL PERFORMANCE (POINTS) ACROSS TREATMENTS: TOBIT REGRESSION The dependent variable is the number of points individuals obtained in each period. Mortality treatment is a dummy variable equal to 1 if subjects were primed with death-related thoughts, whereas it is equal to 0 if subjects were primed with music thoughts. Public feedback is a dummy variable equal to 1 if subjects received a public feedback on individual rank, whereas it is equal to 0 if subjects received a private feedback. Words recall mortality is equal to the total number of death-related words subjects were able to remember during the incidental memory test in the mortality treatments, while Words recall music is the total number of music-related words subjects were able to remember in the music treatments. Loss is equal to 1 if subjects experienced a loss in the recent past and 0 otherwise. Math ability is a categorical variable which captures individuals ability in math as reported by the subjects in the exit questionnaire. Period is a categorical variable, which ranges from 1 to 7 and account for the period of the game. For a more detailed description, see Table (3).

\begin{tabular}{|c|c|c|c|c|c|}
\hline & $a$ & $b$ & $C$ & $d$ & $\mathrm{e}$ \\
\hline \multirow[t]{2}{*}{ Mortality Treatment } & -2.529 & $-5.039 * *$ & $-4.602^{* *}$ & $-4.601^{* *}$ & $-4.636^{* *}$ \\
\hline & $(1.869)$ & $(2.064)$ & $(2.027)$ & $(2.026)$ & $(2.051)$ \\
\hline \multirow[t]{2}{*}{ Public Feedback } & 1.381 & 1.192 & 1.302 & 1.303 & $2.394^{*}$ \\
\hline & $(1.414)$ & $(1.399)$ & $(1.368)$ & $(1.367)$ & $(1.402)$ \\
\hline \multirow{2}{*}{ Public Feedback*Mortality } & 1.148 & 1.823 & 1.517 & 1.516 & 1.514 \\
\hline & $(2.342)$ & $(2.285)$ & $(2.247)$ & $(2.246)$ & $(2.247)$ \\
\hline \multirow[t]{2}{*}{ Words Recall Mortality } & & $0.471^{* * *}$ & $0.461^{* * *}$ & $0.461^{* * *}$ & $0.461^{* * *}$ \\
\hline & & $(0.157)$ & $(0.153)$ & $(0.153)$ & $(0.153)$ \\
\hline \multirow[t]{2}{*}{ Words Recall Music } & & 0.123 & 0.081 & 0.081 & 0.081 \\
\hline & & $(0.215)$ & $(0.212)$ & $(0.211)$ & $(0.212)$ \\
\hline \multirow[t]{2}{*}{ Loss } & & & -0.337 & -0.338 & -0.337 \\
\hline & & & $(0.791)$ & $(0.791)$ & $(0.791)$ \\
\hline \multirow[t]{2}{*}{ Math Ability } & & & $0.611^{* *}$ & $0.611^{* *}$ & $0.611^{* *}$ \\
\hline & & & $(0.264)$ & $(0.264)$ & $(0.264)$ \\
\hline \multirow[t]{2}{*}{ Period } & & & & $0.234^{* * *}$ & $0.360^{* * *}$ \\
\hline & & & & $(0.039)$ & $(0.069)$ \\
\hline \multirow[t]{2}{*}{ Period*Public Feedback } & & & & & $-0.272^{* * *}$ \\
\hline & & & & & $(0.078)$ \\
\hline \multirow[t]{2}{*}{ Period ${ }^{*}$ Mortality } & & & & & 0.009 \\
\hline & & & & & $(0.078)$ \\
\hline Session Dummies & Yes & Yes & Yes & Yes & Yes \\
\hline 11 & -2175 & -2170 & -2168 & -2150 & -2144 \\
\hline $\mathrm{N}$ & 882 & 882 & 882 & 882 & 882 \\
\hline
\end{tabular}

${ }^{*} \mathrm{p}<0.10,{ }^{* *} \mathrm{p}<0.05,{ }^{* * *} \mathrm{p}<0.01$ 
Table 6: ESTIMATION RESULTS INDIVIDUAL PERFORMANCE (POINTS): TOBIT REGRESSION WITH INDIVIDUAL CONTROLS

The dependent variable is the number of points individuals obtained in each period. Mortality Treatment, Public Feedback, Words Recall Mortality, Words Recall Music, Loss, Math Ability, and Period are defined in the same way as in Table (5). Reciprocity is a categorical variable which captures individuals' attitude to reciprocate. Effort Priming and Emotion Priming are categorical variables (from 1 to 5) which measures subjects level of effort and emotion while writing their essay. Agreeableness and Openness are the corresponding behavioural traits as measured through an entry questionnaire. Age is a variable which measures individual age, whereas female is a dummy variable equal to 1 for female participants, and 0 otherwise. Period is a categorical variable, which ranges from 1 to 7 and account for the period of the game. For a more detailed description, see Table (3).

\begin{tabular}{|c|c|c|c|c|c|}
\hline & $\mathrm{a}$ & $\mathrm{b}$ & C & $\mathrm{d}$ & $\mathrm{e}$ \\
\hline Mortality Treatment & $\begin{array}{l}-1.361 \\
(1.558)\end{array}$ & $\begin{array}{l}-3.754^{*} \\
(2.065)\end{array}$ & $\begin{array}{c}-4.604^{* *} \\
(2.017)\end{array}$ & $\begin{array}{l}-3.407 \\
(2.077)\end{array}$ & $\begin{array}{c}-4.038^{* *} \\
(2.054)\end{array}$ \\
\hline Public Feedback & $\begin{array}{c}2.230 \\
(1.432)\end{array}$ & $\begin{array}{c}2.165 \\
(1.392)\end{array}$ & $\begin{array}{c}1.915 \\
(1.429)\end{array}$ & $\begin{array}{c}2.112 \\
(1.395)\end{array}$ & $\begin{array}{l}2.530^{*} \\
(1.399)\end{array}$ \\
\hline Public Feedback*Mortality & $\begin{array}{l}-1.729 \\
(1.979)\end{array}$ & $\begin{array}{l}1.768 \\
(2.224)\end{array}$ & $\begin{array}{c}1.559 \\
(2.230)\end{array}$ & $\begin{array}{c}1.931 \\
(2.237)\end{array}$ & $\begin{array}{l}1.709 \\
(2.235)\end{array}$ \\
\hline Words Recall Mortality & $\begin{array}{l}0.453^{* * *} \\
(0.161)\end{array}$ & $\begin{array}{l}0.436^{* * *} \\
(0.153)\end{array}$ & $\begin{array}{l}0.452^{* * *} \\
(0.153)\end{array}$ & $\begin{array}{l}0.392^{* *} \\
(0.157)\end{array}$ & $\begin{array}{c}0.415^{* * *} \\
(0.152)\end{array}$ \\
\hline Words Recall Music & $\begin{array}{c}0.070 \\
(0.218)\end{array}$ & $\begin{array}{c}0.182 \\
(0.217)\end{array}$ & $\begin{array}{c}0.083 \\
(0.212)\end{array}$ & $\begin{array}{c}0.167 \\
(0.219)\end{array}$ & $\begin{array}{c}0.170 \\
(0.214)\end{array}$ \\
\hline Loss & $\begin{array}{l}-0.380 \\
(0.826)\end{array}$ & $\begin{array}{l}-0.390 \\
(0.783)\end{array}$ & $\begin{array}{l}-0.610 \\
(0.806)\end{array}$ & $\begin{array}{l}-0.521 \\
(0.789)\end{array}$ & $\begin{array}{l}-0.359 \\
(0.783)\end{array}$ \\
\hline Math Ability & $\begin{array}{l}0.635^{* *} \\
(0.277)\end{array}$ & $\begin{array}{l}0.639^{* *} \\
(0.261)\end{array}$ & $\begin{array}{l}0.604^{* *} \\
(0.262)\end{array}$ & $\begin{array}{l}0.627^{* *} \\
(0.261)\end{array}$ & $\begin{array}{l}0.507^{*} \\
(0.275)\end{array}$ \\
\hline Period & $\begin{array}{l}0.322^{* * *} \\
(0.056)\end{array}$ & $\begin{array}{l}0.365^{* * *} \\
(0.054)\end{array}$ & $\begin{array}{l}0.365^{* * *} \\
(0.054)\end{array}$ & $\begin{array}{l}0.365^{* * *} \\
(0.054)\end{array}$ & $\begin{array}{l}0.365^{* * *} \\
(0.054)\end{array}$ \\
\hline Period*Public Feedback & $\begin{array}{c}-0.230^{* * *} \\
(0.080)\end{array}$ & $\begin{array}{c}-0.273^{* * *} \\
(0.078)\end{array}$ & $\begin{array}{c}-0.273^{* * *} \\
(0.078)\end{array}$ & $\begin{array}{c}-0.273^{* * *} \\
(0.078)\end{array}$ & $\begin{array}{c}-0.273^{* * *} \\
(0.078)\end{array}$ \\
\hline Reciprocity & $\begin{array}{c}0.116 \\
(0.470)\end{array}$ & & & & \\
\hline Effort Priming & & & $\begin{array}{c}0.142 \\
(0.477)\end{array}$ & & \\
\hline Emotion Priming & & & $\begin{array}{c}0.456 \\
(0.367)\end{array}$ & & \\
\hline Agreeableness & & $\begin{array}{c}0.099 \\
(0.139)\end{array}$ & & $\begin{array}{c}0.111 \\
(0.140)\end{array}$ & $\begin{array}{c}0.110 \\
(0.138)\end{array}$ \\
\hline Openness & & $\begin{array}{c}0.204 \\
(0.136)\end{array}$ & & $\begin{array}{c}0.212 \\
(0.137)\end{array}$ & $\begin{array}{l}0.224^{*} \\
(0.135)\end{array}$ \\
\hline Age & & & & $\begin{array}{l}-0.091 \\
(0.077)\end{array}$ & \\
\hline Female & & & & $\begin{array}{l}-0.207 \\
(0.683)\end{array}$ & \\
\hline Social Insecurity & & & & & $\begin{array}{c}0.014 \\
(0.459)\end{array}$ \\
\hline Personal Insecurity & & & & & $\begin{array}{l}-0.747^{*} \\
(0.432)\end{array}$ \\
\hline Developmental Insecurity & & & & & $\begin{array}{l}-0.033 \\
(0.431)\end{array}$ \\
\hline Session Dummies & Yes & Yes & Yes & Yes & Yes \\
\hline 11 & -2045 & -2143 & -2143 & -2142 & -2141 \\
\hline $\mathrm{N}$ & 840 & 882 & 882 & 882 & 882 \\
\hline
\end{tabular}


Table 7: DYNAMIC INDIVIDUAL PERFORMANCE (FIRST DIFFERENCE POINTS)

The dependent variable is the first difference (i.e. the difference between two periods) in the number of points. Mortality Treatment, Public Feedback, Words Recall Mortality, Words Recall Music, Loss, Math Ability, Agreeableness, Openness and Period are defined in the same way as in Table (5). Rank 1st (t-1) and Rand 2nd (t-1) are dummies variables equal to 1 if the subject respectively ranked 1st or 2 nd in the previous period.

\begin{tabular}{|c|c|c|c|c|c|}
\hline & $a$ & $\mathrm{~b}$ & c & d & $\mathrm{e}$ \\
\hline \multirow[t]{2}{*}{ Mortality Treatment } & -0.191 & -0.553 & -0.527 & -0.527 & -0.250 \\
\hline & $(0.356)$ & $(0.402)$ & $(0.426)$ & $(0.426)$ & $(0.431)$ \\
\hline \multirow[t]{2}{*}{ Public Feedback } & $-0.815^{* *}$ & $-0.755^{* *}$ & $-0.746^{* *}$ & $-0.746^{* *}$ & $-0.825^{* * *}$ \\
\hline & $(0.328)$ & $(0.303)$ & $(0.304)$ & $(0.304)$ & $(0.307)$ \\
\hline \multirow[t]{2}{*}{ Public Feedback*Mortality } & 0.493 & 0.483 & 0.475 & 0.475 & 0.572 \\
\hline & $(0.481)$ & $(0.469)$ & $(0.492)$ & $(0.493)$ & $(0.480)$ \\
\hline \multirow[t]{2}{*}{ Rank 1st (t-1) } & $-1.232^{* * *}$ & $-1.281^{* * *}$ & $-1.320^{* * *}$ & $-1.322^{* * *}$ & $-1.369^{* * * *}$ \\
\hline & $(0.199)$ & $(0.206)$ & $(0.216)$ & $(0.217)$ & $(0.221)$ \\
\hline \multirow[t]{2}{*}{ Rank 2nd (t-1) } & $-0.778^{* * *}$ & $-0.797^{* * *}$ & $-0.816^{* * *}$ & $-0.819^{* * *}$ & $-0.836^{* * * *}$ \\
\hline & $(0.287)$ & $(0.287)$ & $(0.291)$ & $(0.292)$ & $(0.291)$ \\
\hline \multirow{2}{*}{ Words Recall Mortality } & & $0.049^{*}$ & $0.049^{*}$ & $0.049^{*}$ & $0.043^{*}$ \\
\hline & & $(0.025)$ & $(0.025)$ & $(0.025)$ & $(0.025)$ \\
\hline \multirow[t]{2}{*}{ Words Recall Music } & & -0.040 & -0.046 & -0.046 & -0.009 \\
\hline & & $(0.059)$ & $(0.060)$ & $(0.060)$ & $(0.060)$ \\
\hline \multirow[t]{2}{*}{ Loss } & & & -0.097 & -0.097 & -0.114 \\
\hline & & & $(0.151)$ & $(0.151)$ & $(0.141)$ \\
\hline \multirow[t]{2}{*}{ Math Ability } & & & 0.050 & 0.050 & 0.064 \\
\hline & & & $(0.062)$ & $(0.062)$ & $(0.062)$ \\
\hline \multirow[t]{2}{*}{ Period } & & & & -0.026 & -0.026 \\
\hline & & & & $(0.047)$ & $(0.047)$ \\
\hline \multirow[t]{2}{*}{ Agreeableness } & & & & & 0.018 \\
\hline & & & & & $(0.030)$ \\
\hline \multirow[t]{2}{*}{ Openness } & & & & & $0.084^{* * *}$ \\
\hline & & & & & $(0.025)$ \\
\hline \multirow[t]{2}{*}{ Constant } & $1.380^{* * *}$ & $1.484^{* * *}$ & $1.373^{* * *}$ & $1.491^{* * *}$ & 0.430 \\
\hline & $(0.234)$ & $(0.270)$ & $(0.309)$ & $(0.377)$ & $(0.521)$ \\
\hline Session Dummies & Yes & Yes & Yes & Yes & Yes \\
\hline $\mathrm{N}$ & 756 & 756 & 756 & 756 & 756 \\
\hline
\end{tabular}

${ }^{*} \mathrm{p}<0.10,{ }^{* *} \mathrm{p}<0.05,{ }^{* * *} \mathrm{p}<0.01$ 
Table 8: DYNAMIC INDIVIDUAL PERFORMANCE (RANK)

The dependent variable is individual rank in each period. The lower the rank, the higher the relative position of the individual in the peer group. Mortality Treatment, Public Feedback, Words Recall Mortality, Words Recall Music, Loss, Math Ability, Agreeableness, Openness and Period are defined in the same way as in Table (5). Rank 1st (t-1) and Rand 2nd (t-1) are dummies variables equal to 1 if the subject respectively ranked 1st or 2nd in the previous period.

\begin{tabular}{|c|c|c|c|c|}
\hline & $a$ & $b$ & $c$ & d \\
\hline \multirow{2}{*}{ Mortality Treatment } & -0.038 & 0.100 & -0.115 & -0.115 \\
\hline & (0.172) & $(0.213)$ & $(0.247)$ & $(0.244)$ \\
\hline \multirow{2}{*}{ Public Feedback } & 0.004 & -0.010 & -0.006 & 0.012 \\
\hline & (0.132) & (0.136) & (0.118) & (0.154) \\
\hline \multirow[t]{2}{*}{ Public Feedback*Mortality } & -0.007 & -0.012 & -0.032 & -0.027 \\
\hline & $(0.211)$ & $(0.238)$ & (0.241) & $(0.239)$ \\
\hline \multirow[t]{2}{*}{ Rank 1st (t-1) } & $-0.926^{* * *}$ & $-0.846^{* * *}$ & $-1.021^{* * *}$ & $-1.051^{* * *}$ \\
\hline & $(0.086)$ & $(0.091)$ & $(0.118)$ & $(0.135)$ \\
\hline \multirow{2}{*}{ Rank 2nd (t-1) } & $-0.488^{* * *}$ & $-0.453^{* * *}$ & $-0.639^{* * *}$ & $-0.573^{* * *}$ \\
\hline & $(0.085)$ & $(0.084)$ & $(0.117)$ & (0.149) \\
\hline \multirow[t]{2}{*}{ Words Recall Mortality } & & $-0.031^{* *}$ & $-0.037^{* * *}$ & $-0.037^{* * * *}$ \\
\hline & & $(0.012)$ & $(0.014)$ & $(0.014)$ \\
\hline \multirow[t]{2}{*}{ Words Recall Music } & & 0.006 & 0.006 & 0.007 \\
\hline & & $(0.022)$ & (0.019) & (0.020) \\
\hline \multirow[t]{2}{*}{ Loss } & & 0.070 & 0.091 & 0.095 \\
\hline & & $(0.074)$ & (0.078) & $(0.078)$ \\
\hline \multirow{2}{*}{ Math Ability } & & $-0.066^{* *}$ & $-0.059^{* *}$ & $-0.060^{* *}$ \\
\hline & & $(0.027)$ & $(0.027)$ & $(0.027)$ \\
\hline \multirow[t]{2}{*}{ Period } & & 0.004 & 0.004 & 0.005 \\
\hline & & $(0.012)$ & $(0.012)$ & $(0.012)$ \\
\hline \multirow[t]{2}{*}{ Rank 1st $(\mathrm{t}-1)^{*}$ Mortality } & & & $0.363^{* *}$ & $0.367^{* *}$ \\
\hline & & & (0.169) & (0.168) \\
\hline \multirow[t]{2}{*}{ Rank 2nd (t-1)*Mortality } & & & $0.365^{* *}$ & $0.362^{* *}$ \\
\hline & & & (0.162) & $(0.161)$ \\
\hline Rank 1st (t-1)*Public Feedback & & & & $\begin{array}{c}0.060 \\
(0.165)\end{array}$ \\
\hline Rank 2nd (t-1)*Public Feedback & & & & -0.132 \\
\hline \multirow[t]{2}{*}{ Constant } & $1.448^{* * *}$ & $1.580^{* * *}$ & $1.669^{* * *}$ & $1.656^{* * *}$ \\
\hline & $(0.114)$ & (0.155) & $(0.150)$ & (0.153) \\
\hline Session Dummies & Yes & Yes & Yes & Yes \\
\hline $\mathrm{N}$ & 756 & 756 & 756 & 756 \\
\hline
\end{tabular}




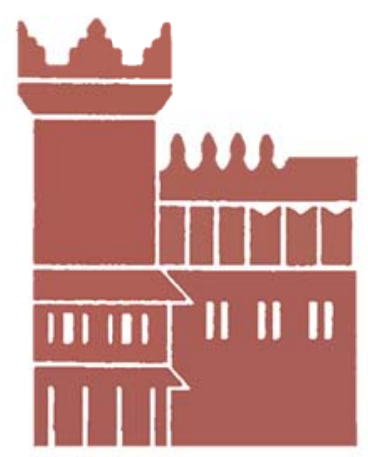

Alma Mater Studiorum - Università di Bologna DEPARTMENT OF ECONOMICS

Strada Maggiore 45

40125 Bologna - Italy

Tel. +39051 2092604

Fax +390512092664

http://www.dse.unibo.it 